\title{
De novo mutation in MEN1 is not associated with parental somatic mosaicism
}

\section{Dear Editor,}

Multiple endocrine neoplasia type 1 (MEN1-OMIM $\# 131100$ ) is characterized by the co-occurrence of tumors in at least two of the following three endocrine tissues: parathyroid, endocrine pancreas and anterior pituitary (Thakker 2014). Familial MEN1 follows an autosomal dominant mode of inheritance, and germline mutations in the MEN1 gene at 11q13 can be detected in affected family members (Chandrasekharappa et al. 1997). Mutations in the CDKN1B gene (CDKN1B, KIP1 and OMIM \#600778) have been also reported in MEN1 families but are far less frequent (Pellegata et al. 2006). Germline mutations in the MEN1 gene have also been detected in seemingly sporadic MEN1 cases and have been referred to as de novo mutations. Indeed, an often quoted number in MEN1-focused reports is $10 \%$ of the cases showing a de novo mutation (Bassett et al. 1998). The occurrence of a mutation in an affected individual with none of the parents exhibiting MEN1-suggestive features may be attributed to non-paternity, non-penetrant mutant allele, gonadal mosaicism or parental germline/somatic mosaicism (Koper \& Lamberts 2000). The assignment of a de novo MEN1 gene mutation in previous studies was based on lack of a parental phenotype (Peppa et al. 2009), inferred haplotype (Bassett et al. 1998) or lack of the proband's mutation in either parent using Sanger sequencing (Teh et al. 1998, Rix et al. 2004). No published study used deep sequencing to assess the possibility of parental, low-level mosaicism.

The diagnostic criteria of MEN1 include having at least two of the three predominant neoplasms in at least one case (Thakker 2014). Clinical associations other than benign and malignant tumors are scarce in MEN1. Notably, there is a single report of an MEN1-affected individual who also exhibited a distinct phenotype that includes autism and dysmorphic features and harbors a $570 \mathrm{~kb}$ deletion at 11q13 encompassing the MEN1 gene (Mohrmann et al. 2011). Here we evaluated the possibility of low-level germline parental mosaicism in a Jewish Ashkenazi family where the proband also exhibits autism.

\section{Patients and clinical phenotype}

This study was approved by the local Ethics Committee, and each participant gave an informed consent. Participants were clinically evaluated by history and physical examination and diagnosis was further supported by biochemical testing and imaging analyses. The proband, a Jewish Ashkenazi male born in 1989, was diagnosed with mild autistic disorder at age 5 years and is treated since with Clotiapine $2.5 \mathrm{mg} /$ day. At age 24, he was diagnosed with pituitary micro-adenoma based on elevated prolactin (PRL) levels (2200 IU/L (45-375)), and MRI showing $7 \mathrm{~mm}$ pituitary micro-adenoma. He was treated with Cabergoline $0.5 \mathrm{mg} /$ week resulting in a return of the PRL levels to near normal. At age 26 years, he was diagnosed with primary hyperparathyroidism with elevated levels of calcium and PTH $(11.3 \mathrm{mg} / \mathrm{mL}, 40 \mathrm{pg} / \mathrm{mL}$ (normal range for kit 4.6-38), respectively) with imaging (ultrasound and Sestamibi parathyroid scan) showing a single adenoma of the lower left parathyroid. Based on persistent hypercalcemia at a young age, osteoporosis (bone density at age 26 years (hologic) $Z$ scores at femoral neck -3.0 and lumbar spine -2.9) and ongoing anorexia, surgical removal of the parathyroid gland was performed in November of 2015. At surgery, the lower left parathyroid adenoma and the thymus were surgically resected with intra-operative PTH reduction from $355 \mathrm{pg} / \mathrm{mL}$ to $63 \mathrm{pg} / \mathrm{mL}$ (normal range for kit 14-72), with normocalcemia and normo-PTH achieved and maintained until the time of reporting.

The proband's father was diagnosed with primary hyperparathyroidism at age 63 years based on hypercalcemia and elevated PTH levels $(10.9 \mathrm{mg} / \mathrm{mL}$, $80 \mathrm{pg} / \mathrm{mL}$ (normal range for kit 14-72)). Imaging studies

Published by Bioscientifica Ltd 
(ultrasound and Sestamibi parathyroid scan) could not document any abnormal parathyroid tissue.

Both parents were unrelated to each other, and there is no family history of endocrine tumors on either parental side. The proband has a healthy brother born 1994 .

\section{Germline mutation analysis of the MEN1 gene}

Genomic DNA was isolated from peripheral blood leukocytes of the proband and both parents using a commercially available kit (wizard genomic DNA purification kit, Promega) and using the manufacturer's suggested protocol. The proband's DNA was sent by the treating physician for analysis of a multi-gene panel (InVitae, San Francisco, CA, USA). Subsequent to defining the proband's mutation, his DNA and that of his parents underwent genotyping for the specific MEN1 mutation by using both Sanger sequencing and deep sequencing (using Miseq platform). The primers used for PCR of the genotyped mutation-containing region are Forward 5-CTGATCTGTGCCCTCCCTTC-3; Reverse 5-TCAAAACGGCCTAGGGACTG-3.

\section{Paternity testing}

Paternity was ascertained by applying a commercially available kit (Aneufast, Wollerau, Switzerland) and following the manufacturer's protocol to the proband and both his parents.

\section{MEN1 genetic analysis}

Invitae testing showed that the proband harbored a germline heterozygous nonsense mutation c.1213C->T in exon 9 of the MEN1 gene, which leads to a premature stop codon, p.Gln405X. In addition, a heterozygous variant was detected in the KIT gene, rs138585275 p.Thr274Met, which is classified as likely benign.

The existence of the MEN1 gene mutation in the proband was subsequently confirmed using Sanger sequencing and repeat deep sequencing using a different DNA extraction. Neither parent harbored the pathogenic MEN1 mutation using either Sanger sequencing or deep sequencing (X1000 coverage of the mutation). The father harbored the rare p.Thr274Met sequence variant in the KIT gene, and paternity testing revealed that both parents are indeed the proband's parents (data not shown).
In the present study, the MEN1 truncating mutation undoubtedly underlies the MEN1-phenotype in the proband. Although the MEN1 germline mutation could be detected both by using Sanger sequencing as well as deep sequencing in the proband, neither parent was shown to carry the mutation by either sequencing technique. This finding conclusively excludes low-level parental germline mosaicism as the cause of this de novo MEN1 mutation. As non-paternity was excluded, the other molecular mechanisms that may account for this phenomenon are gonadal mosaicism or a bona fide de novo mutation restricted to the proband. Interestingly, Rix and coworkers described a de novo MEN1 mutation (p.Leu444Pro) in a phenotypically sporadic MEN1 case, and the mutation could not be detected in either parent by Sanger Sequencing (Rix et al. 2004). Yet, an identical MEN1 mutation was previously reported in a large Italian family (Cetani et al. 1999), raising the possibility of a low-level parental mosaicism in the case by Rix and coworkers (Rix et al. 2004). In the MEN1 mutation database (http://www. umd.be/MEN1/), a truncating mutation in the same codon (p.Leu444X) in a single family is also noted. Previous studies have not effectively excluded the possibility of a low-level parental mosaicism, as they did not employ deep sequencing analysis. It remains to be seen what the relative contribution of each of these possible molecular mechanisms to the emergence of de novo MEN1 mutations.

Based on the fact that the father was diagnosed with biochemical primary hyperparathyroidism (despite the lack of any demonstrable parathyroid tumor), one would expect the father to harbor the familial MEN1 mutation. The fact that he does not have any evidence of harboring the familial mutation may imply that the father represents a phenocopy of primary hyperparathyroidism in the context of MEN1, a phenomenon not previously described, to the best of our knowledge.

Another issue raised by this case is the clinical association between MEN1 phenotype and autism. This is only the second case (Mohrmann et al. 2011) in which such an association was reported, and the first where no major deletions involving the MEN1 gene have been noted. In all likelihood, this is a co-occurrence of two distinct disease entities, as the rate of autism is reportedly 1:68 individuals and even higher (1:42) among boys (http://www.cdc.gov/ncbddd/autism/data.html).

In conclusion, a de novo MEN1 gene mutation in this family is not associated with low-level parental mosaicism, the father may represent the first described case of MEN1 phenocopy.

Published by Bioscientifica Ltc 
Yael Laitman ${ }^{1}$

Anat Jaffe 2

Hagit Schayek ${ }^{1}$

Eitan Friedman ${ }^{1,3}$

${ }^{1}$ The Susanne Levy Gertner Oncogenetics Unit, Institute of Human Genetics, Chaim Sheba Medical Center, Tel-Hashomer, Israel 2Endocrinology and Diabetes Unit, Hillel Yaffe Medical Center, Hadera, Israel ${ }^{3}$ The Sackler School of Medicine, Tel-Aviv University, Tel-Aviv, Israel

(Correspondence should be addressed to E Friedman; email: feitan@post.tau.ac.il or eitan.friedman@sheba.health.gov.il)

\section{Declaration of interest}

The authors declare that there is no conflict of interest that could be perceived as prejudicing the impartiality of the research reported.

\section{Funding}

This research did not receive any specific grant from any funding agency in the public, commercial or not-for-profit sector.

\section{Acknowledgements}

The authors thank the family members for their cooperation.

\section{References}

Bassett JH, Forbes SA, Pannett AA, Lloyd SE, Christie PT, Wooding C, Harding B, Besser GM, Edwards CR, Monson JP, et al. 1998 Characterization of mutations in patients with multiple endocrine neoplasia type 1. American Journal of Human Genetics 62 232-244. (doi:10.1086/301729)

Cetani F, Pardi E, Cianferotti L, Vignali E, Picone A, Miccoli P, Pinchera A \& Marcocci C 1999 A new mutation of the MEN1 gene in an Italian kindred with multiple endocrine neoplasia type 1. European Journal of Endocrinology 140 429-433. (doi:10.1530/ eje.0.1400429)

Chandrasekharappa SC, Guru SC, Manickam P, Olufemi SE, Collins FS, Emmert-Buck MR, Debelenko LV, Zhuang Z, Lubensky IA, Liotta LA, et al. 1997 Positional cloning of the gene for multiple endocrine neoplasia-type 1. Science 276 404-407. (doi:10.1126/ science.276.5311.404)

Koper JW \& Lamberts SW 2000 Sporadic endocrine tumours and their relationship to the hereditary endocrine neoplasia syndromes. European Journal of Clinical Investigation 30 493-500. (doi:10.1046/j.1365-2362.2000.00666.x)

Mohrmann I, Gillessen-Kaesbach G, Siebert R, Caliebe A \& Hellenbroich Y 2011 A de novo $0.57 \mathrm{Mb}$ microdeletion in chromosome 11q13.1 in a patient with speech problems, autistic traits, dysmorphic features and multiple endocrine neoplasia type 1 . European Journal of Medical Genetics 54 e461-e464. (doi:10.1016/j. ejmg.2011.04.006)

Pellegata NS, Quintanilla-Martinez L, Siggelkow H, Samson E, Bink K, Höfler H, Fend F, Graw J \& Atkinson MJ 2006 Germ-line mutations in p27kip1 cause a multiple endocrine neoplasia syndrome in rats and humans. PNAS 103 15558-15563. (doi:10.1073/pnas.0603877103)

Peppa M, Boutati E, Kamakari S, Pikounis V, Peros G, Koutsodontis G, Metaxa-Mariatou V, Economopoulos T, Raptis SA \& Hadjidakis D 2009 Novel germline mutations of the MEN1 gene in Greek families with multiple endocrine neoplasia type 1. Clinical Endocrinology $\mathbf{7 0}$ 75-81. (doi:10.1111/j.1365-2265.2008.03308.x)

Rix M, Hertel NT, Nielsen FC, Jacobsen BB, Hoejberg AS, Brixen K, Hangaard J \& Kroustrup JP 2004 Cushing's disease in childhood as the first manifestation of multiple endocrine neoplasia syndrome type 1. European Journal of Endocrinology 151 709-715. (doi:10.1530/ eje.0.1510709)

Teh BT, Kytölä S, Farnebo F, Bergman L, Wong FK, Weber G, Hayward N, Larsson C, Skogseid B, Beckers A, et al. 1998 Mutation analysis of the MEN1 gene in multiple endocrine neoplasia type 1, familial acromegaly and familial isolated hyperparathyroidism. Journal of Clinical Endocrinology and Metabolism 83 2621-2626. (doi:10.1210/ jc.83.8.2621)

Thakker RV 2014 Multiple endocrine neoplasia type 1 (MEN1) and type 4 (MEN4). Molecular and Cellular Endocrinology 386 2-15. (doi:10.1016/j.mce.2013.08.002)

Received in final form 24 October 2016

Accepted 25 October 2016

Accepted Preprint published online 31 October 2016
C 2017 Society for Endocrinology Printed in Great Britain
Published by Bioscientifica Ltd. 